\title{
Research on interfacial cracking of a Cr coating/steel substrate with and without laser pre-quenching treatment under thermal fatigue loading
}

\author{
Ban-Quan Yang ${ }^{1,}$, , Guang-Nan Chen ${ }^{2}$, Xue-Jun Chen ${ }^{3}$, Wei-Hai Sun ${ }^{1}$, \\ Hong-Qian Chen ${ }^{1}$, Jing-Wen Pan $^{1}$ and Ying Chen ${ }^{1}$
}

${ }^{1}$ Division of Engineering Mechanics, Department of Mechanical Engineering, Academy of Armored Force Engineering, No. 21, Du-Jia-Kan, Chang-Xin-Dian, Beijing 100072, P. R. China

${ }^{2}$ Laboratory of surface modification, Institute of mechanics, Chinese Academy of Sciences, No. 15 Bei-si-huan-xi Road, Beijing 100190, P. R. China

${ }^{3}$ School of Applied Sciences, University of Science and Technology Beijing, No. 30 Xue-Yuan Road, Beijing 100083, P. R. China

ayangbq1022@sina.com

Keywords: Interfacial cracking; $\mathrm{Cr}$ coating/laser pre-quenched steel substrate system; $\mathrm{Cr}$ coating/original steel substrate system; Thermal fatigue loading.

\begin{abstract}
The interfacial cracking behaviors of a chromium (Cr) coating/laser pre-quenched steel substrate system and a $\mathrm{Cr}$ coating/original steel substrate system under thermal fatigue loading were investigated in this work. The experiment results show that the $\mathrm{Cr}$ coating on the pre-quenched substrate surface exhibited a higher resistance of interfacial cracking than that of the $\mathrm{Cr}$ coating on the original substrate surface under the same loading condition. This indicates the technology of laser pre-quenching of steel substrate surface prior to plating the $\mathrm{Cr}$ coating can improve the interfacial adhesion properties between the coating and substrate.
\end{abstract}

\section{Introduction}

Chromium coatings have been widely used on engineering parts and composites such as piston rings, work rolls and aircraft landing gear etc. due to their high hardness, excellent wear and corrosion resistance, high melting point and low coefficient of friction $[1,2]$. However, under the severe service conditions such as thermal fatigue loading, gas erosion and severe stressing, cracking is usually caused at the coating or the substrate/chromium interface, which will result in the spallation of the chromium coatings from the substrate $[3,4]$. The spallation of the coating from the substrate means the failure of the coating-substrate system to a certain extent. In these severe service conditions, the thermal fatigue loading is often considered to be the dominating factor that causes the engineering parts or composites failure, and the fracture behaviors and failure mechanisms of coatings under this loading have been the subject of considerable research $[5,6]$. With more and more severe operating conditions, the single traditional chromium plating cannot meet the practical requests. In order to satisfy the practical requests, a novel technology of laser pre-quenching of steel substrate surface prior to plating the $\mathrm{Cr}$ coating has been presented $[7,8]$. This technology can greatly improve the bearing capability of the $\mathrm{Cr}$ coating/steel substrate system in practical conditions, as stated in Ref. [9]. Some mechanisms responsible for the improvement have been revealed, such as the generation of residual compressive stress and hardness improvement of the steel substrate surface [10], the finer microstructure of the interface as well as the coating itself [9] and the decrease of the crack driving force in the hardened layer by residual compressive stress and yield strength improvement by the technology [11-13]. However, the failure process and modes of this material system and the effect of this technology on the interfacial adhesion properties between the coating and substrate under thermal fatigue loading are still lacking. The interfacial adhesion properties of a coating on its substrate are considered to be crucial intrinsic parameters determining performance and reliability of coating-substrate system. In this work, the fracture behaviors under thermal fatigue loading of a $\mathrm{Cr}$ 
coating/laser pre-quenched steel substrate system and a $\mathrm{Cr}$ coating/original steel substrate system are investigated. The behaviors and interfacial adhesion properties between the two material systems are compared.

\section{Experimental procedure and results}

The substrate material was as-quenched and tempered 30CrNi2MoV (AISI 3034) steel (main chemical ingredients: $0.28 \mathrm{C}, 0.7 \mathrm{Cr}, 2.27 \mathrm{Ni}, 0.20 \mathrm{Mo}, 0.21 \mathrm{~V}$, all in wt. \%). The steel plate $99 \mathrm{~mm} \times 16.5 \mathrm{~mm} \times 5 \mathrm{~mm}$ was quenched using a continuous $\mathrm{CO}_{2}$ laser with beam power $600 \mathrm{~W}$, beam diameter $5 \mathrm{~mm}$ and beam scanning velocity $10 \mathrm{~mm} / \mathrm{s}$. The beam interval between two laser tracks is large enough so that the interaction between the neighboring tracks can be ignored. Their laser-quenched surfaces were mechanically ground and polished. The $\mathrm{Cr}$ coatings composed of low-contraction (LC) and high-contraction (HC) Cr were prepared by the commercial electroplating processing of the practical chromium-coated parts. The LC-Cr layer about $20 \mu \mathrm{m}$ thick was pre-deposited as an interlayer with the commercial plating bath of chromic acid $\left(250 \mathrm{gl}^{-1}\right)$ and sulfuric acid $\left(2.5 \mathrm{gl}^{-1}\right)$, at a temperature of $85{ }^{\circ} \mathrm{C}$ and a current density of $60 \mathrm{~A} / \mathrm{dm}^{2}$. The HC-Cr plate approximately $110 \mu \mathrm{m}$ thick was deposited at a lower bath temperature and a lower current density. The dimension of the specimens is designed to be $6 \mathrm{~mm} \times 5 \mathrm{~mm} \times 5 \mathrm{~mm}$, and the Cr coating is designed to be on two perpendicular and intersecting faces of the specimen.

In this work, the number of specimens of the $\mathrm{Cr}$ coating /laser pre-quenched steel substrate is 8 , so is $\mathrm{Cr}$ coating/original steel substrate specimens. The representative optical microscopes of the cross section of the two types of the specimens are shown in Fig.1 (a) and (b).
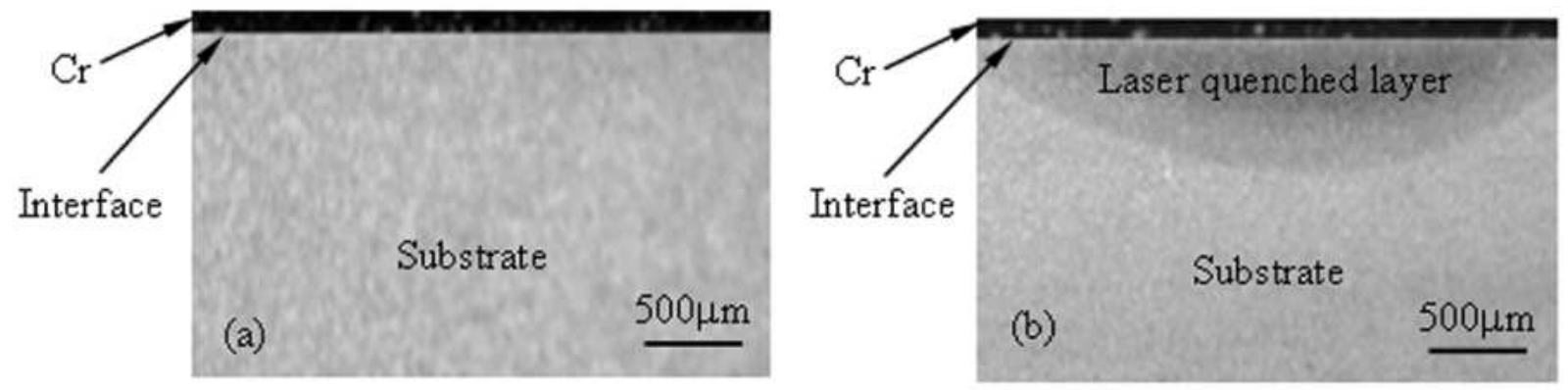

Fig. 1. The optical photo of the cross section of the two types of specimens: (a) Cr coating /original steel substrate; (b) Cr coating/laser pre-quenched steel substrate.

In this experiment, all the specimens were heated simultaneously in an electromagnetic oven at $650 \mathrm{C}^{0}$ with a heating rate of approximately $200 \mathrm{C}^{0} / \mathrm{min}$. The experiment setup is shown in Fig. 2 .

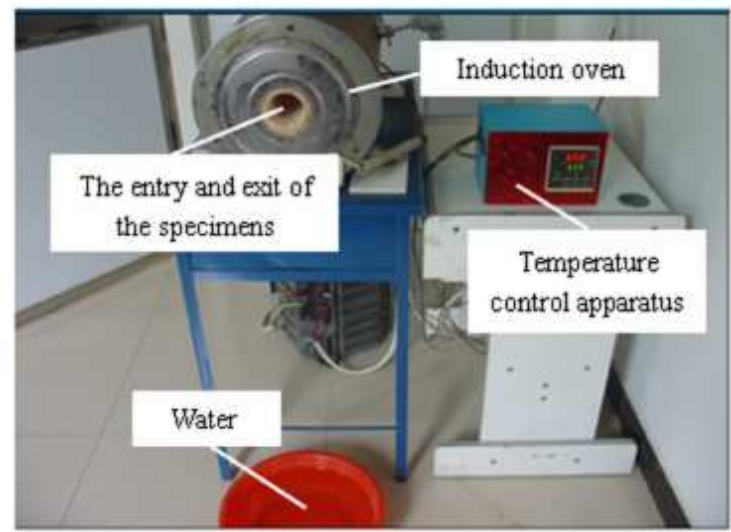

Fig. 2. The experiment setup. 
After the temperature of the specimens remained $650 \mathrm{C}^{0}$, they were quickly removed from the induction oven, and quenched with water at temperature of $12 \mathrm{C}^{0}$. The heated and quenched process repeated.

Generally, failure in coatings is associated with the build-up of stress mainly due to the thermal expansion mismatch. During thermal cycling, when the specimens were taken out from the high temperature oven and quickly quenched in water, very large stress developed in the coating due to the difference of thermal expansion coefficients between the coating and the substrate, which can be given by the following expression:

$$
\sigma_{C}=\frac{E_{C} \Delta \alpha}{1-v_{C}} \Delta T
$$

Where $\sigma_{C}$ is the stress developed in the coating, $E_{C}$ and $v_{C}$ are Young's modulus and Poisson ratio of the coating respectively, $\Delta \alpha$ is the difference in coefficients of thermal expansion between the coating and the substrate, and $\Delta T$ is the change in temperatures.

After the thermal cycle times reached the designed number, specimens respectively belonging to the two systems were taken out. Then, they were mechanically ground and polished. The representative optical microscope of the cross section of the corner of the specimens after 650,1000 cycles are shown in Figs.3 and 4, respectively.
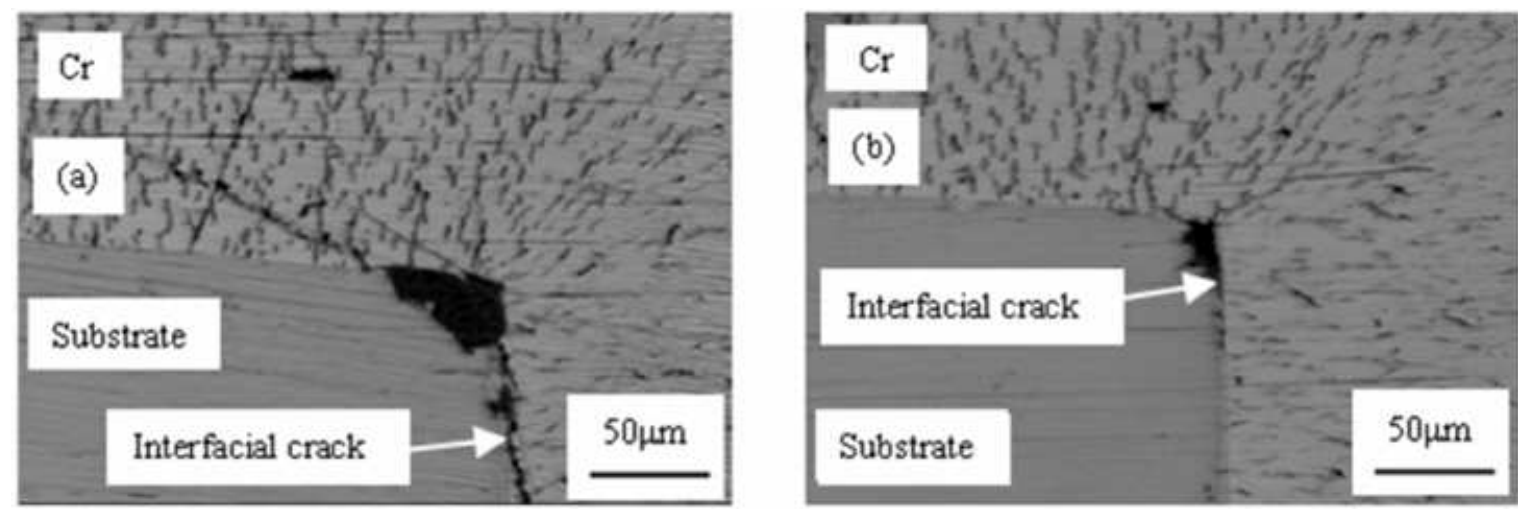

Fig. 3. The optical microscope of the cross section of the corner of the two material systems after 650 cycles: (a) Cr coating/original steel substrate; (b) Cr coating /laser pre-quenched steel substrate.
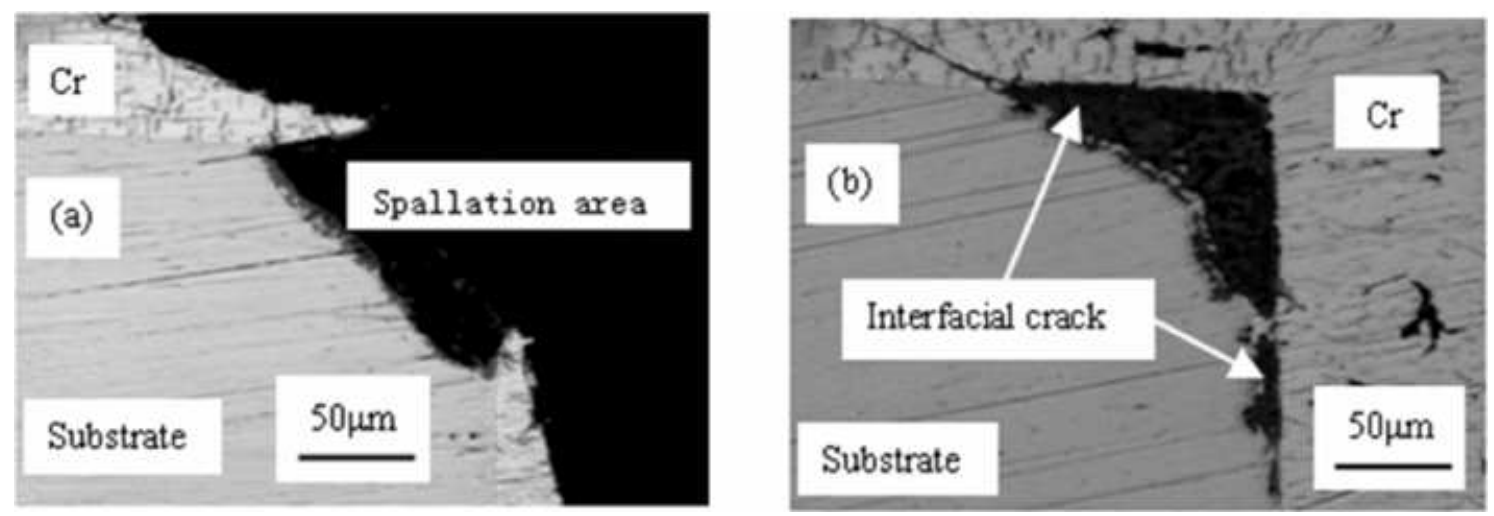

Fig. 4. The optical microscope of the cross section of the corner of the two material systems after 1000 cycles: (a) Cr coating/original steel substrate; (b) Cr coating /laser pre-quenched steel substrate.

\section{Discussions and results}

From Fig.3, it can be seen that the interfacial cracking has occurred after 650 cycles, but the length of the interfacial crack of the pre-quenched substrate system is much shorter than that of the original substrate system. From Fig.4, it can be seen that the spallation of the coating on the original substrate 
has occurred after 1000 cycles, but the Cr coating on the pre-quenched substrate has not yet. From these results, we can obtain that the Cr coating on the pre-quenched substrate surface exhibited a higher resistance of interfacial cracking than that of the $\mathrm{Cr}$ coating on the original steel substrate surface under the same thermal loading. Generally, the higher resistance of interfacial cracking means better interfacial adhesion properties, such as the interfacial fracture toughness and bonding strength. These results indicate the technology of laser pre-quenching of steel substrate surface prior to plating the $\mathrm{Cr}$ coating can improve the interfacial adhesion properties.

\section{Acknowledgements}

The authors gratefully acknowledge the financial support of the Innovative Science Foundation of Academy of Armored Force Engineering (Grant No. 2011CJ025), the financial support of the Postdoctoral Science Foundation of China (Grant No. 20100470149), the financial support of the National Natural Science Foundation of China (Grant No. 51171026, 51075398, 10802007).

\section{References}

[1] J.Sim and D.K. Aspinwall: J. Mater. Process. Technol. Vol. 92-93 (1999), p.218.

[2] L.Fedrizzi, S.Rossi, F.Bellei and F.Deflorian: Wear Vol. 253 (2002), p. 1173.

[3] B.Lawton: Wear Vol 251(2001), p. 827.

[4] S.Sopok, C.Richard and S.Dunn: Wear Vol 258 (2005), p. 659.

[5] X.J. Chen, K. Zhang, G.N. Chen and G.X. Luo: Surf. Coat. Technol. Vol 201 (2006), p. 815.

[6] X.J. Chen, K. Zhang, G.N. Chen and G.X. Luo: Int. J. Solids Struct. Vol 43(2006), p. 6424.

[7] W. Harald, S. Uvc, Germany Patent: DE19918794.

[8] G.N. Chen, G.X. Luo, K. Zhang, X.Y. Xu, H. Shen, H.M. Yan and D. Rao: Acta. ArmamentII(Suppl) Vol. 24 (2003), p. 6 (in Chinese).

[9] H.X. Li, G.N. Chen, G.X. Zhang, K. Zhang and G.X. Luo: Surf. Coat. Technol. Vol 201 (2006), p. 902.

[10] J. Grum and P. Žerovnik: Heat. Treat. Vol 25(1993), p. 32.

[11] B.Q. Yang, K. Zhang, G.N. Chen, G.X. Luo and J.H. Xiao: Acta. Mater. Vol. 55 (2007), p. 4349.

[12] B.Q. Yang, G.N. Chen, K. Zhang, G.X. Luo and J.H. Xiao: Journal of Academy of Armorced Force Engineering. Vol. 23 (2009), p. 76(in Chinese).

[13] B.Q. Yang and P. Li: Journal of Academy of Armorced Force Engineering. Vol. 25 (2011), p. 88(in Chinese). 
Digital Manufacturing \& Automation III

10.4028/www.scientific.net/AMM.190-191

Research on Interfacial Cracking of a Cr Coating/Steel Substrate with and without Laser PreQuenching Treatment under Thermal Fatigue Loading

10.4028/www.scientific.net/AMM.190-191.543

\section{DOI References}

[2] L. Fedrizzi, S. Rossi, F. Bellei and F. Deflorian: Wear Vol. 253 (2002), p.1173.

http://dx.doi.org/10.1016/S0043-1648(02)00254-5

[11] B.Q. Yang, K. Zhang, G.N. Chen, G.X. Luo and J.H. Xiao: Acta. Mater. Vol. 55 (2007), p.4349.

http://dx.doi.org/10.1016/j.actamat.2007.04.002 